\title{
The Copenhagen City Heart Study Experience
} and its Key Contributions to Chronic Obstructive Pulmonary Disease

Peter Lange, DMSc ${ }^{1,2}$ and Jørgen Vestbo, DMSc ${ }^{3,4}$

${ }^{1}$ Department of Public Health, Section of Social Medicine, University of Copenhagen, Denmark; ${ }^{2}$ Medical Department O, Respiratory Section, Herlev and Gentofte Hospital, Copenhagen University Hospital, Copenhagen, Denmark; ${ }^{3}$ Division of Infection, Immunity and Respiratory Medicine, School of Biological Sciences, The University of Manchester, Manchester, UK; ${ }^{4}$ Manchester University NHS Foundation Trust, Manchester Academic Health Science Centre, Manchester, UK

\section{ABSTRACT}

Although the principal aim of the Copenhagen City Heart Study (CCHS) was to investigate risk factors for ischaemic heart disease, it already started including spirometry and a questionnaire on respiratory symptoms from its start in 1976. Longitudinal design including five examination rounds and follow-up of hospitalisations, mortality and medically treated exacerbations of chronic obstructive pulmonary disease (COPD) gave a great opportunity to study different aspects of the natural history of COPD. Since 1988, more than 100 papers on different aspects of obstructive lung diseases have been published. Among the most quoted are publications on lung function decline in asthma, trajectories leading to COPD, analyses describing positive association between physical activity and COPD, role of nutritional status for prognosis of COPD, and a nested intervention study showing no effect of an inhaled corticosteroid (ICS) on lung function decline among individuals with mild COPD. The present review describes some of these studies. (BRN Rev. 2018;4(4):231-44)

Corresponding author: Peter Lange, peter.lange@sund.ku.dk

Key words: Asthma. Chronic obstructive pulmonary disease. Epidemiology. Natural history. 


\section{BACKGROUND}

In the 1980s, COPD epidemiology in Denmark, the rest of the Nordic countries and Europe in general, was heavily influenced by the findings by Fletcher et al. ${ }^{1,2}$ in their study of London postal workers. Although several cohort studies from England and the United States (US) had improved our understanding of chronic lung disease ${ }^{3-6}$, they had mainly stimulated prevalence studies and analyses of cross-sectional data. With the seminal findings by Fletcher et al. ${ }^{1,2}$, exploring longitudinal changes in lung function, the focus on assessing longitudinal decline in forced expiratory volume in one second $\left(\mathrm{FEV}_{1}\right)$ as a marker of development of airflow limitation and subsequent disease progression, enabled the study of risk factors and modifiers for an excess decline in lung function, primarily $\mathrm{FEV}_{1}$. This of course required longitudinal assessment of lung function, but a number of cohort studies in the Nordic countries had been set up in the late 1960s and early 1970s, mainly inspired by the Framingham study ${ }^{7}$, and among these was the Copenhagen City Heart Study $(\mathrm{CCHS})^{8}$. Other cohorts in Europe and the US had been set up around the same time, the most prominent of which are listed in a review by Kohansal et al..

\section{THE COPENHAGEN STUDY}

The original aim of the CCHS was to investigate the distribution of cardiovascular disease in the general population of Copenhagen and the risk factors for the incidence of heart disease and other chronic conditions. In contrast to earlier studies, the majority of the invited participants were women. The funds for the first study were provided by The Danish Heart Association, and the leading physician Anders Tybjærg Hansen, who was Professor of Cardiology at the University of Copenhagen during the 1970s, recruited two younger cardiologists, Peter Schnohr and Gorm Jensen, and a statistician, Jørgen Nyboe, to the steering committee. Initially, there were no plans to include lung function testing. However, as the study happened to take part in rooms right next to the hospital's physiology laboratory, the Danish respiratory physiologist Johan Georg suggested the cardiologists to include spirometry as one of the tests. It was accepted, and the foundation for respiratory epidemiology in Copenhagen was laid. It was taken up by another physiologist, Steffen Groth, and Peter Lange who ensured the inclusion of spirometry at subsequent visits.

For the first examination round, which was conducted from 1976 to 1978, a sample of 19,698 subjects, aged 20 years or older and living in the part of Copenhagen surrounding the Copenhagen University Hospital (Rigshospitalet), was selected at random from the national Danish Civil Registration System, after age stratification in 5-year age groups. In total, 14,223 subjects participated in the initial survey (response rate $81 \%$ ). They were all re-invited to participate in later surveys along with additional subjects in the youngest age groups. The number of participants in the second survey was 12,923, in the third 10,135, 6237 in the fourth examination and, finally, 4466 in the fifth and most recent survey (Fig. 1).

Although the main focus was on cardiovascular risk factors, the first examination already included spirometry, as the Framingham Heart study suggested that reduced vital 
At each examination:

- spirometry \& comprehensive questionnaire covering symptoms, lifestyle and exposures

- and from 1991-4 increasing numbers of biomarkers: CRP, fibrinogen, eosinophils
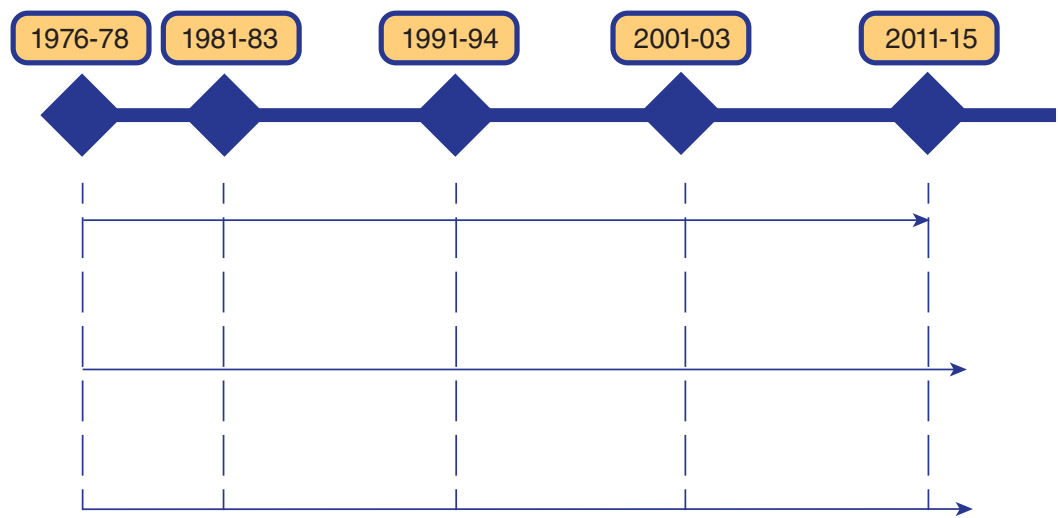

Evolution of FEV

- from 5 years to 38 years

Medically treated exacerbations

between 1995 and 2017

Figure 1. Flow chart of The Copenhagen City Heart Study.

CRP: C-reactive protein; $\mathrm{FEV}_{1}$ : forced expiratory volume in one second.

capacity may be a predictor for heart failure and perhaps also for ischaemic heart disease ${ }^{10}$. Thus, spirometry was performed at all examinations of the CCHS: pre-bronchodilator measurements only in the first, second, fourth and fifth examination, whereas post-bronchodilator values were additionally obtained in the third examination in the subgroup of participants with $\mathrm{FEV}_{1}$ /forced vital capacity $(\mathrm{FVC})<0.7$. At the initiation of the study, smoking prevalence in Copenhagen in both men and women was more than $50 \%$ and the participants answered a detailed questionnaire on their smoking habits, including the type of tobacco smoked (cigarettes, cheroots, cigars and pipe) and whether they inhaled or not. In addition, the questionnaire included information on asthma and chronic bronchitis. During the evolution of the study, the respiratory questionnaire was expanded to include an increasing number of respiratory symptoms and questions on recurrent respiratory infections. The participants also gave blood for various analyses and for biobanking.

All participants were subsequently followed through linkage with Danish registries on vital status and hospital admission. For analyses of medically treated exacerbations of COPD, the CCHS database was linked with the Danish Prescription Registry, which holds complete information on all out-of-hospital dispensed prescriptions. 


\section{SMOKING AND CHRONIC OBSTRUCTIVE PULMONARY DISEASE}

During the 1980s, following the seminal study of Fletcher et al. ${ }^{1}$, which defined two overlapping but distinct syndromes, the more benign hypersecretory disorder (defined by presence of chronic mucus hypersecretion $=$ chronic bronchitis) and the more serious obstructive syndrome (defined as chronic airflow limitation), the tendency was to investigate these two conditions separately, rather than combining them into $\mathrm{COPD}^{1}$. This was also the case in the CCHS. At that time there was an interest in whether filter cigarettes were less harmful than plain cigarettes and whether reduction in the number of cigarettes smoked had some health advantages. In this context, the early publications from CCHS showed that lung function decline was not affected by the presence of filters and that inhalation habits did not affect lung function decline in cigarette smokers ${ }^{11,12}$. In pipe smokers however, respiratory symptoms and lung function decline were less pronounced in those who reported not to inhale while smoking. The CCHS studies focusing on the number of cigarettes smoked, smoking cessation and reduction could demonstrate a dose-dependent relationship with regard to lung function decline and a beneficial effect of quitting on both lung function decline and remittance of respiratory symptoms ${ }^{13,14}$. Reducing smoking had some effect in younger light smokers but not in the elderly nor in the heavy smokers.

Subsequent studies focused on the possible sex differences in the susceptibility to smoking and suggested that smoking may have a slightly higher impact on the lung function of females than males, and that females suffer a higher risk of being admitted to hospital for COPD $^{15}$.

With the increase of the duration of the CCHS, new possibilities for analyses became apparent. In 2006, approximately 30 years after the initiation of the study, we focused on the risk of developing COPD in relation to smoking and changes in smoking habits. Within the study population, we identified approximately 8045 men and women aged 30-60 years with normal lung function at baseline and followed their lung function and mortality from COPD. The 25-year incidence of moderate and severe COPD was $20.7 \%$ in continuous smokers and $3.6 \%$ in never smokers, and $92 \%$ of the COPD-related deaths occurred in subjects who were current smokers at the beginning of the follow-up period. Smoking cessation, especially early in the follow-up period, decreased the risk of developing COPD substantially compared with continuous smoking. Overall, the absolute risk of developing COPD defined as presence of chronic airflow limitation was at least $25 \%$, which is higher than was previously estimated ${ }^{16}$ (Fig. 2). These findings were in line with findings from Northern Sweden ${ }^{17}$.

\section{OTHER RISK FACTORS AFFECTING DEVELOPMENT AND PROGRESSION OF CHRONIC OBSTRUCTIVE PULMONARY DISEASE}

It is a well-known clinical phenomenon that patients with a low body mass index (BMI) suffer a poorer prognosis than those with maintained BMI. However, on a population level, a high BMI carries the major mortality risk $^{18}$, albeit not for respiratory mortality 


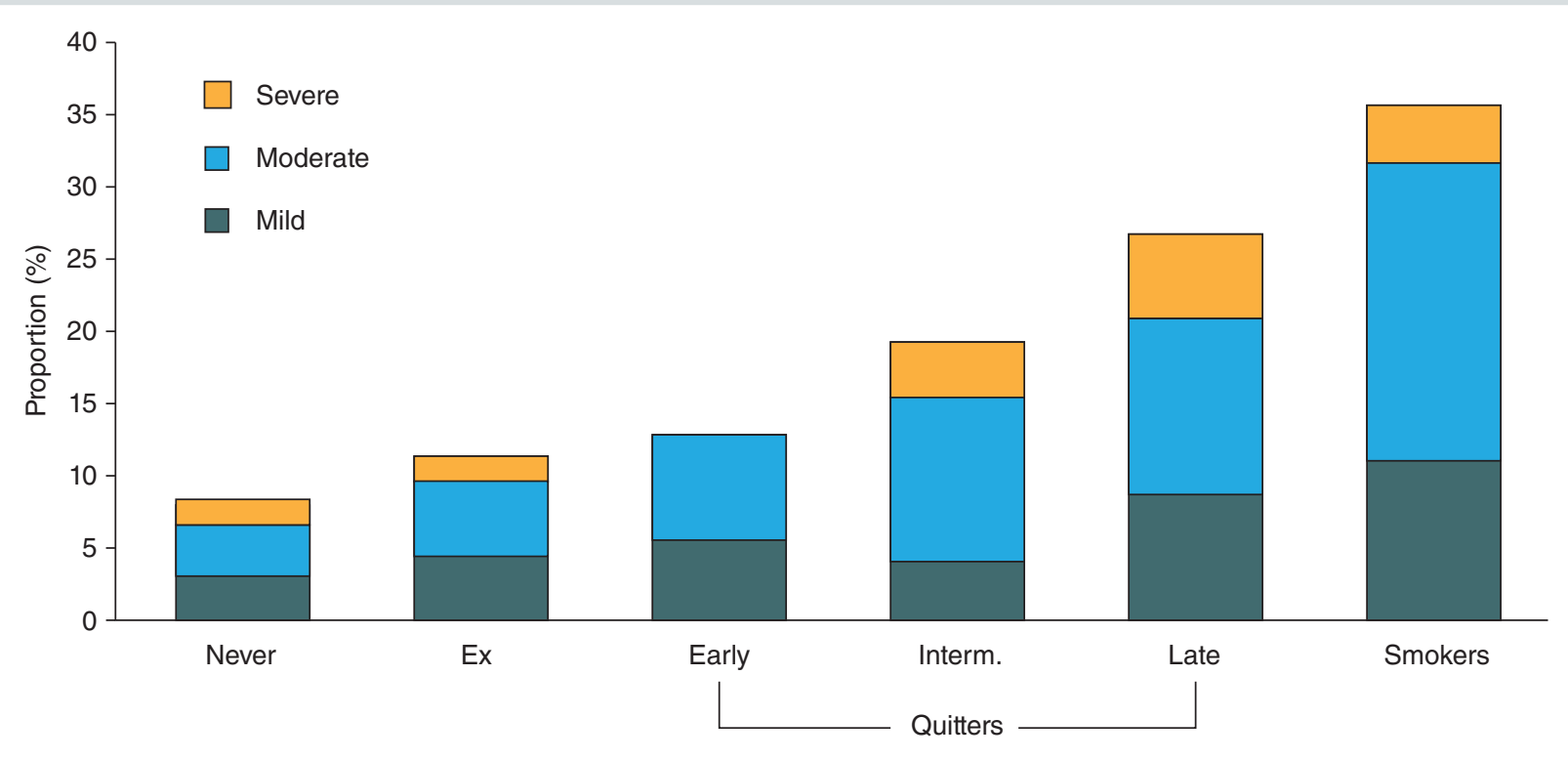

FIgURE 2. Cumulative incidence of COPD according to GOLD 1-4 grades for men and women combined (reproduced with permission from Løkke A et al. ${ }^{16}$. (C) 2018 BMJ Publishing Group Ltd \& British Thoracic Society. All rights reserved).

COPD: chronic obstructive pulmonary disease; GOLD: Global Initiative for Obstructive Lung Disease; Interm.: intermediate.

according to more recent surveys ${ }^{17}$. In the CCHS, we could show a clear association between low BMI and respiratory as well as overall mortality, whereas in subjects with severe airflow limitation there was a steady increase in survival with increasing $\mathrm{BMI}^{20}$.

In a subsequent longitudinal analysis, we found that five-year changes in BMI were also associated with mortality although not as strongly as baseline BMI. In subjects with severe airflow limitation, an increase in BMI was associated with improved prognosis in those with a BMI $<25 \mathrm{~kg} / \mathrm{m}^{2}$, whereas the opposite was true for those being overweight or obese $\mathrm{e}^{21}$.

However, many factors other than smoking and BMI impact respiratory health. Inspired by not least the Whitehall studies from London showing a marked influence of socioeconomic status (SES) on health, we used education and income as proxies for SES and found that low SES was associated with a mean $\mathrm{FEV}_{1}$ almost $300 \mathrm{~mL}$ lower than in individuals with high SES, a feature independent of age ${ }^{22}$. Low SES was also associated with higher risk of respiratory admissions and when refined using social position instead of the crude SES categories, the associations remained ${ }^{23}$. A more recent study investigated how long-term prognosis of established COPD is influenced by $\mathrm{SES}^{24}$. Adjusting for sex, age, $\mathrm{FEV}_{1}$ in percentage of predicted values, dyspnoea, frequency of previous exacerbations and smoking, we observed that shorter school education (in comparison with university education), was associated with a higher risk of 
COPD exacerbations (approximate hazard ratio [HR] 1.6) and all-cause mortality (approximate HR 2). Our conclusion was that even in an economically well-developed country with a tax-funded health care system as Denmark, low SES is associated with a poorer prognosis of COPD.

Together with groups from Barcelona and Maastricht, the CCHS data were analysed to investigate the association between the level of physical activity and changes in physical activity and the development and prognosis of COPD. The analyses suggested that individuals with COPD who engage in regular physical activity have a lower risk of both COPD admissions and mortality ${ }^{25}$. Longitudinal lung function analyses showed that moderate-to-high levels of regular physical activity were associated with reduced lung function decline and a lower COPD risk among smokers ${ }^{26}$. The relationship between changes in physical activities and outcomes was more complex: in participants with COPD with low baseline physical activity, no differences were found in survival between unchanged or increased physical activity at follow-up. However, a decline to low physical activity at follow-up was associated with an increased mortality risk in subjects with and without COPD ${ }^{27}$. Overall, the observational data from CCHS suggest that it is important to assess and encourage physical activity in the earliest stages of COPD in order to maintain the physical activity level as high as possible, as this is associated with better prognosis. Several other studies focused on additional risk factors. One study of importance for the clinician showed a significant association between gastro-oesophageal reflux and exacerbations ${ }^{28}$.

\section{THE IMPORTANCE OF CHRONIC BRONCHITIS}

One of the main issues in COPD epidemiology - and the focus on the London study by Fletcher et al. ${ }^{1}$ - was the association between chronic bronchitis (chronic mucus hypersecretion [CMH]) and decline in lung function. The background was the British Hypothesis, claiming an association between recurrent lower respiratory tract infections and the development of chronic airflow limitation. This hypothesis was rejected by Fletcher et al. ${ }^{1}$ using $\mathrm{CMH}$ as a proxy for recurrent bronchial infections, and the notion of $\mathrm{CMH}$ being an innocent bystander was supported by the frequently quoted mortality study by Peto et al. ${ }^{29}$ showing that $\mathrm{CMH}$ provided very little prognostic information regarding mortality once $\mathrm{FEV}_{1}$ was taken into account.

However, the prevalence of $\mathrm{CMH}$ was considerably lower in Copenhagen than in the London study and it was therefore likely that a "true association" could have been overlooked in the London study where the higher prevalence could be viewed as a response to higher levels of air pollution and therefore "noise". The first Copenhagen analyses focused on mortality and showed that, although there was only a small excess mortality associated with $\mathrm{CMH}$ in subjects with good lung function, the excess mortality associated with $\mathrm{CMH}$ was significant in those with low $\mathrm{FEV}_{1}{ }^{30}$. Prescott et al. ${ }^{31}$ subsequently showed that the excess mortality in those with $\mathrm{CMH}$ was likely due to terminal pneumonia/infectious exacerbations and in a specific analysis of risk factors for pneumonia admission in the general population, CMH was also a risk factor ${ }^{32}$. Subsequent analyses of $\mathrm{CMH}$ and $\mathrm{FEV}_{1}$ decline 
showed a significant association contrasting the findings by Fletcher et $\mathrm{al}^{1}$. (Fig. 3) as well as an association with increased risk of hospital admission, and we hypothesised that $\mathrm{CMH}$ may be a marker of ongoing inflammation rather than infection ${ }^{33}$. A subsequent paper showed that, although $\mathrm{CMH}$ is associated with $\mathrm{FEV}_{1}$ decline, presence of $\mathrm{CMH}$ per se is not indicative of pre-COPD as suggested by the Global Initiative for Obstructive Lung Disease (GOLD) when launching GOLD grade $0^{34}$, the main reason being that a significant number of smokers without $\mathrm{CMH}$ went on to develop COPD, and pointing to an at-risk population would carry the risk of wrongly labelling other smokers at not being at risk ${ }^{35}$.

\section{NATURAL HISTORY OF OBSTRUCTIVE LUNG DISEASE}

The longitudinal design of the CCHS allows studies describing long-term prognosis of respiratory diseases. One of the early studies focused on lung function decline in individuals with self-reported asthma from the first to the third examination, comprising three measurements of lung function over a 15-year period $^{36}$. The analyses showed that the decline in $\mathrm{FEV}_{1}$ was greater among the subjects with asthma than among those without the disease. This was observed among both men and women, and among both smokers and non-smokers. Consequently, at the age of 60 , a 175-cm-tall non-smoking man without asthma had an average $\mathrm{FEV}_{1}$ of 3 litres, as compared with 2 litres for a man of similar age and height who smoked and had asthma.

The revised GOLD document from $2011^{37}$ introducing the clinical COPD groups A-D inspired

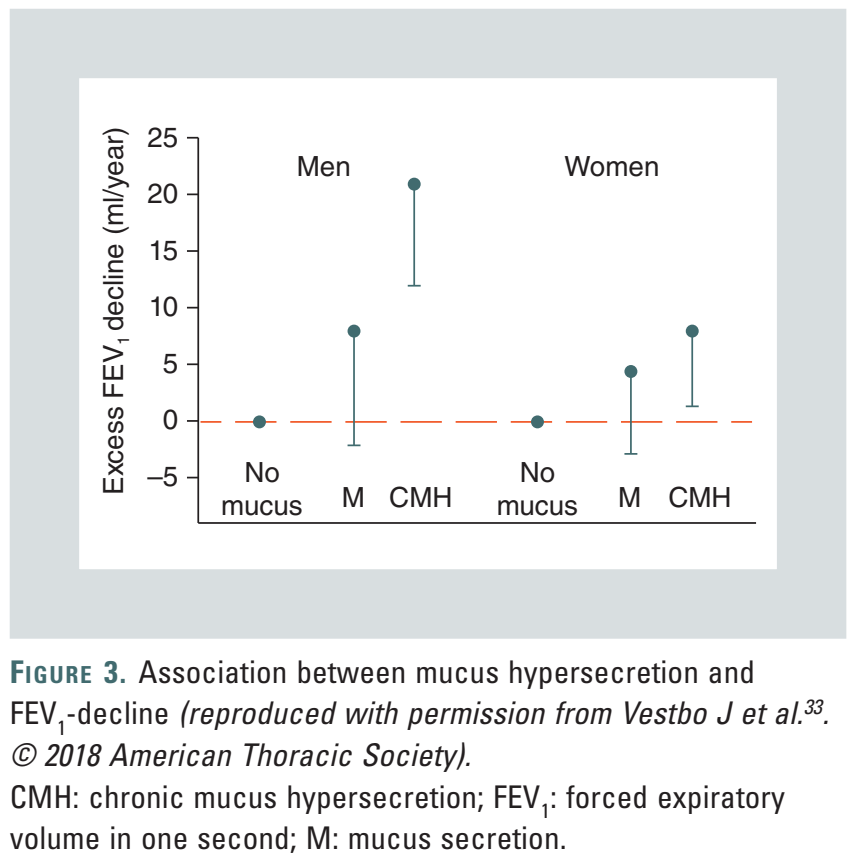

us to investigate the ability of this new classification to predict hospitalisations and mortality due to COPD. In these analyses we combined the CCHS with its "sister study", the Copenhagen General Population Study. The latter is a prospective epidemiologic study that recruits more than 100,000 subjects, representative of the general population, and collects genotypic and phenotypic data of relevance to a wide range of health-related problems. With regard to the questionnaire and the examination of the participants, this study uses a similar methodology as CCHS. The analyses showed that, in comparison with the previous uni-dimensional GOLD stratification based on lung function only (GOLD 1-4), the new multi-dimensional A-D stratification identified a higher number of individuals at substantial risk of exacerbations and disease progression and thus needing special attention ${ }^{38}$. Interestingly, we found that the survival of group B was poorer that of group $\mathrm{C}$, despite lower lung function in the latter (Fig. 4). Thus, severe dyspnoea was associated with poor 

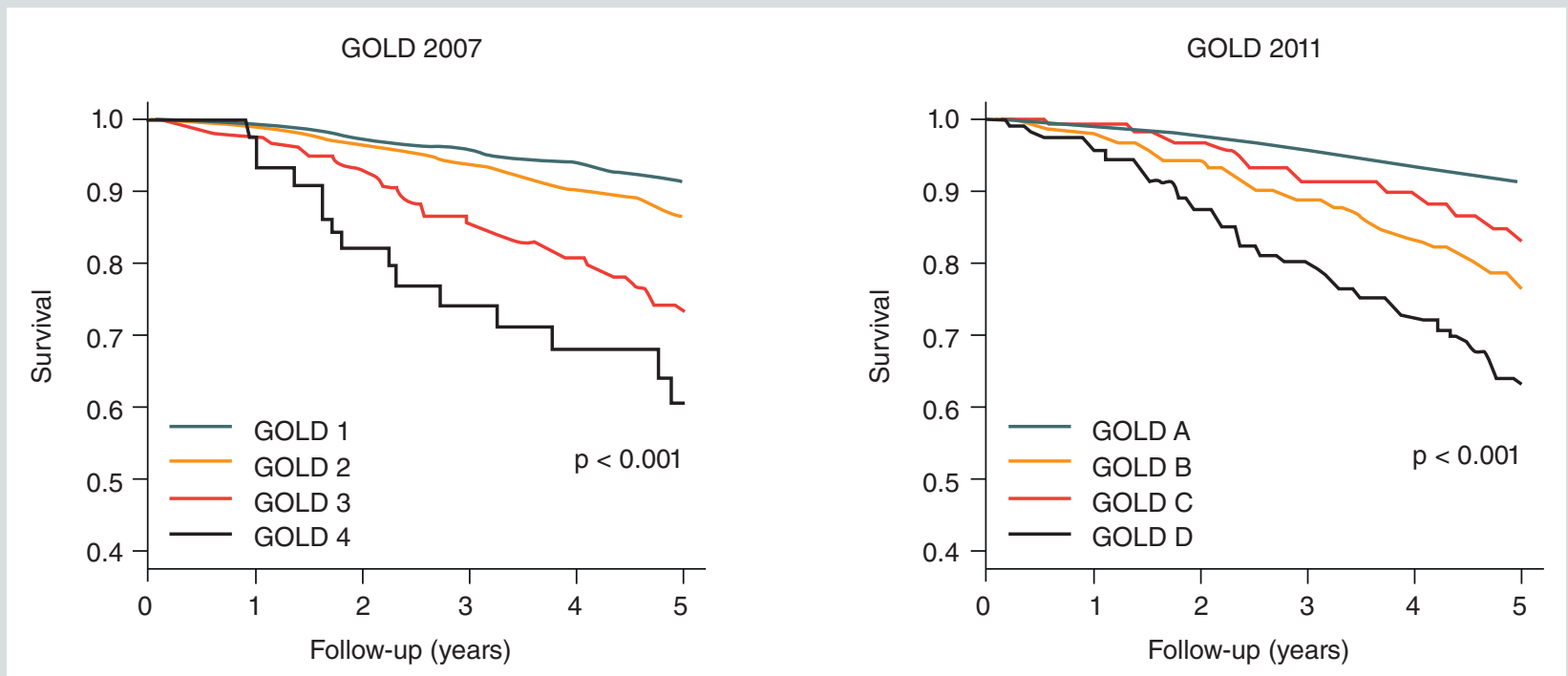

FIgURE 4. Survival according to GOLD 2007 and GOLD 2011 classification (reproduced with permission from Lange P et al. ${ }^{38}$. (C) 2018 American Thoracic Society).

GOLD: Global Initiative for Obstructive Lung Disease.

survival irrespective of level of lung function and warrant special attention. Our results suggested that the poor prognosis associated with more severe dyspnoea symptoms in group B could be due to presence of cardiovascular disease and cancer in this subgroup.

With the longer follow-up, it became possible to examine trajectories of $\mathrm{FEV}_{1}$ leading to COPD. The inspiration for this came from two sources: first, Fletcher \& Peto's BMJ paper $^{2}$ contained a figure showing how initial low lung function could be a risk factor for chronic airflow limitation later in life; secondly, several studies of cohorts of COPD patients had shown that decline in $\mathrm{FEV}_{1}$ was much lower than anticipated given their COPD $^{39-42}$. This resulted in one of the most interesting and challenging CCHS projects. In this study, the CCHS database was combined with the Framingham Offspring Cohort and the Lovelace Smokers Cohort. The participants were subdivided into 4 trajectories defined based on lung function $\left(\mathrm{FEV}_{1} \geq 80 \%\right.$ or $<80 \%$ of the predicted value) at inclusion into the cohort and the presence or absence of COPD at the last study visit ${ }^{43}$. Among 657 participants with $\mathrm{FEV}_{1}$ of less than $80 \%$ of the predicted value before 40 years of age, $174(26 \%)$ had COPD after 22 years of observation, whereas among 2207 persons who had a baseline $\mathrm{FEV}_{1}$ of at least $80 \%$ of the predicted value before 40 years of age, $158(7 \%)$ developed COPD.

Approximately half of the 332 persons with COPD at the end of the observation period had had a normal $\mathrm{FEV}_{1}$ before 40 years of age and a rapid decline in $\mathrm{FEV}_{1}(53 \mathrm{ml} / \mathrm{yr})$, whereas the remaining half had had a low $\mathrm{FEV}_{1}$ in 


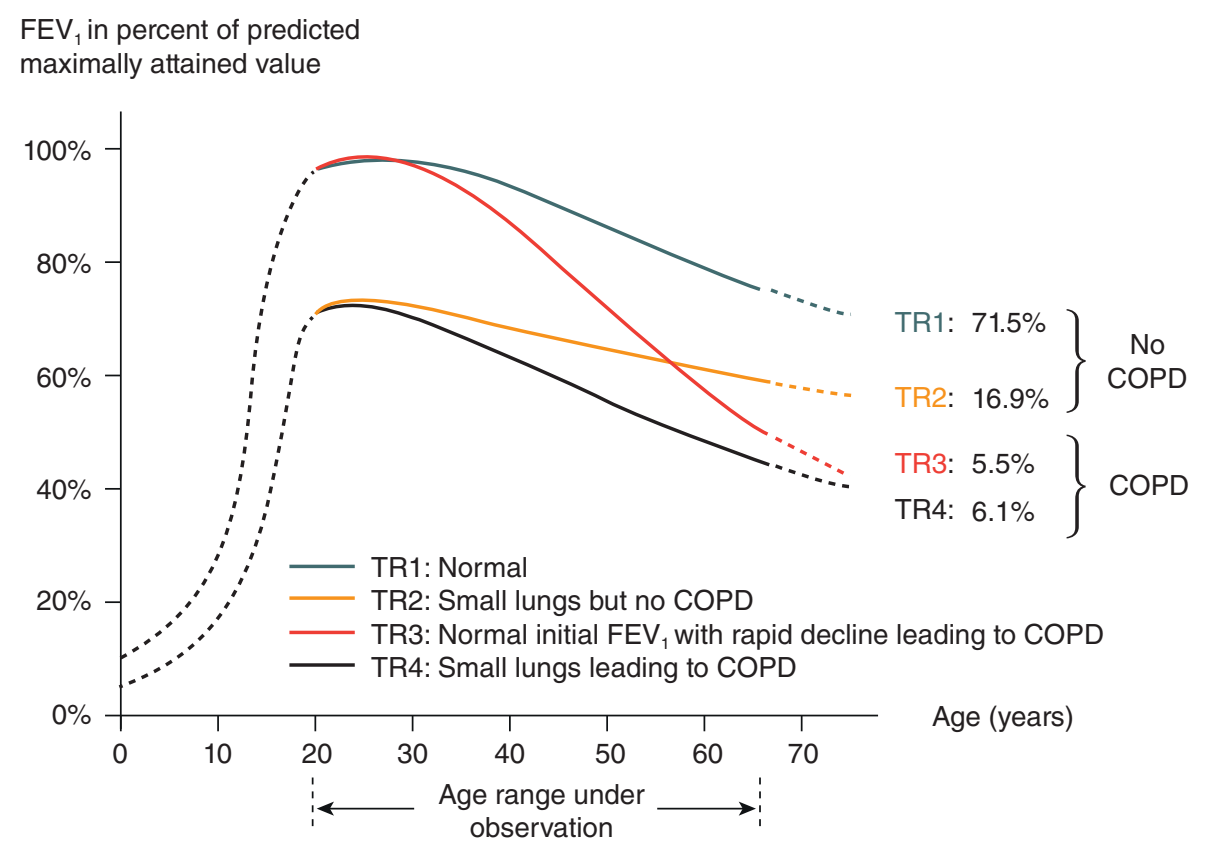

Figure 5. Distribution of individuals into four $\mathrm{FEV}_{1}$-trajectories (reproduced with permission from Lange $P$ et al. ${ }^{43}$ ). COPD: chronic obstructive pulmonary disease; $\mathrm{FEV}_{1}$ : forced expiratory volume in one second. TR: trajectories.

early adulthood and a subsequent normal decline in $\mathrm{FEV}_{1}(27 \mathrm{ml} / \mathrm{yr})$, despite similar smoking exposure (Fig. 5). This study confirmed previous hypothesis that low $\mathrm{FEV}_{1}$ in early adulthood is an important risk factor for COPD and that accelerated decline in $\mathrm{FEV}_{1}$ is not an obligate feature of COPD.

After the publication of the Global Initiative for Asthma (GINA)- GOLD document on asthma-COPD overlap syndrome (ACOS) in 2014, we revisited the question of long-term prognosis in individuals with asthmatic features and those with COPD. We expanded the observation period and analysed both $\mathrm{FEV}_{1}$ decline for 18 years and hospital admissions and survival for 22 years. We defined six different subgroups: healthy never-smokers, ever-smokers without asthma and COPD, those with asthma with low cumulated smoking exposure and no airflow limitation, those with COPD, those with asthma-COPD overlap (ACO) with asthma onset before the age of 40 years, and those with ACO with asthma onset after the age of 40 years. The estimated decline in $\mathrm{FEV}_{1}$ in $\mathrm{ACO}$ with early-onset asthma was $27 \mathrm{~mL}$, which did not differ significantly from the decline of $21 \mathrm{~mL}$ per year in healthy never-smokers. $\mathrm{FEV}_{1}$ decline in individuals with $\mathrm{ACO}$ with late-onset asthma was $50 \mathrm{~mL}$ and in the COPD group we observed an annual decline of $40 \mathrm{~mL}$. Hazard ratios for hospital admissions due to exacerbations of asthma or COPD were highest in 


\begin{tabular}{|c|c|c|c|c|c|c|c|c|c|c|c|c|}
\hline & \multirow{2}{*}{$\begin{array}{l}\text { Participants } \\
\text { (n) }\end{array}$} & \multicolumn{4}{|c|}{ Respiratory mortality } & \multicolumn{4}{|c|}{ All-cause mortality } & \multicolumn{3}{|l|}{ Survival decreaset } \\
\hline & & $\begin{array}{l}\text { Events } \\
(\mathrm{n}[\mathrm{s}])\end{array}$ & $\begin{array}{l}\text { Hazard ratio } \\
\left(95 \times(0)^{\circ}\right.\end{array}$ & pvalue & & $\begin{array}{l}\text { Events } \\
(\mathrm{n}[\mathrm{KD})\end{array}$ & $\begin{array}{l}\text { Hazard ratio } \\
\left(95 \%()^{*}\right.\end{array}$ & pvalue & & $\begin{array}{l}\text { Survival decrease } \\
(95 \%(1)\end{array}$ & pvalue & \\
\hline Adjusted for age and sex & 8382 & $356(7 \%)$ & & & & 3964 (50\%) & & & & & & \\
\hline Never-smokers without disease & e 2199 & $47(3 x)$ & 1.00 (reference) & & & $812(41 \mathrm{~N})$ & 1.00 (reference) & & & 0.0 (reference) & & \\
\hline Ever-smokers without disease & 5435 & $172(5 \times)$ & $1.90(1.37-2 \cdot 64)$ & 0,0001 & (a) & 2598 (51\%) & $1.46(1.35-1.58)$ & $\$ 00001$ & - & $38(30$ to 45$)$ & $<00001$ & \\
\hline Asthma & 158 & $11(8 x)$ & $4.59(2.38-8.86)$ & $\infty 00001$ & $\mapsto-1$ & $60(39 \%)$ & $1.40(1.08-1.82)$ & 0.01 & tor & $3.3(1.0$ to 5.5$)$ & 0.004 & \\
\hline COPD & 320 & $46(35 \%)$ & $10.45(6-88-15-88)$ & .00001 & •r & $270(87 \times)$ & $2.76(2.40-3.18)$ & $\$ 0.0001$ & $\bullet$ & $10-1$ (8.6 to 11.5$)$ & $<0.0001$ & \\
\hline ACO with early asthmu onset & 68 & $6(12 \%)$ & $8.17(3-49-19-15)$ & $<00001$ & $\bullet$ & $38(57 \times)$ & $2.55(184-3.53)$ & $\$ 00001$ & $\mapsto$ & $9.3(5.4$ to 13.1$)$ & $<0,0001$ & $\because$ \\
\hline ACO with late asthma onset & 202 & $74(72 \%)$ & $31-86(21-94-46-28)$ & $<0,0001$ & $\bullet$ & $186(93 \%)$ & $3.72(3 \cdot 16-4 \cdot 37)$ & $\$ 0001$ & $\bullet$ & $12.8(11.1$ to 146$)$ & ) $<0.0001$ & \\
\hline $\begin{array}{l}\text { Adjusted for age, sex, BML, } \\
\text { and } F E V_{2} \% \text { of predicted value }\end{array}$ & 8367 & $354(6 \%)$ & & & & $3953(50 x)$ & & & & & & \\
\hline Never-smokers without disease & 2199 & $47(3 \%)$ & 1.00 (reference) & & & $812(41 \%)$ & 1.00 (reference) & & & 0.0 (reference) & & \\
\hline Ever-smokers without disease & 5435 & $172(5 \times)$ & $1.66(1 \cdot 19-2 \cdot 30)$ & 0.003 & & 2598 (51\%) & $1.37(1.26-1.48)$ & $\$ 0001$ & - & $3.0(2.3$ to 38$)$ & $<0,0001$ & \\
\hline Asthma & 143 & $9(7 \times)$ & $2.58(1.25-5.31)$ & 0.01 & $\mapsto-1$ & $49(35 \%)$ & $1.05(0.79-1.41)$ & $0-73$ & -1 & $0.5(-1.8$ to $2 \cdot 7)$ & 0.67 & \\
\hline COPD & 320 & $46(35 *)$ & $369(2 \cdot 34-5 \cdot 83)$ & $\$ 00001$ & rer & $270(87 \times)$ & $1.75(1.50-2.04)$ & .00001 & 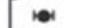 & $5.4(3.9$ to 6.9$)$ & $\$ 0.0001$ & \\
\hline ACO with early asthma onset & 68 & $6(12 \%)$ & $2.30(0.95-5.55)$ & 0.06 & $\bullet-1$ & $38(57 \%)$ & $1.44(1.03-2-01)$ & 0.03 & $\bullet-1$ & $3-4(-0-2$ to $7-0)$ & 0.06 & $\rightarrow$ \\
\hline ACO with late asthma onset & 202 & $74(72 \mathrm{x})$ & $6-36(399-10-13)$ & $<0001$ & $\bullet$ & $186(93 \%)$ & $1.81(1-50-2-17)$ & $\$ 0001$ & $\bullet$ & $5 \cdot 4(3-6$ to $7 \cdot 2)$ & $<00001$ & \\
\hline $\begin{array}{l}\text { Adjusted for age, sex, BML, } \\
\text { and pack-years }\end{array}$ & 581 & $124(42 \%)$ & & & & $485(85 \%)$ & & & & & & \\
\hline COPD & 320 & $46(35 \%)$ & 1.00 (reference) & & & $270(87 \%)$ & 1.00 (reference) & & & $0-0$ (reference) & & \\
\hline $\mathrm{ACO}$ with early asthma onset & 67 & $6(12 x)$ & $1.07(0.45-2.57)$ & 0.88 & & $37(56 \%)$ & $0-99(0.69-1-41)$ & $0.94 \mapsto$ & -1 & $0.0(-3-4$ to $3-4)$ & $>0.99 \mapsto$ & \\
\hline \multirow[t]{3}{*}{ ACO with late asthma onset } & 194 & $72(7 \times)$ & $351(2 \cdot 38-5 \cdot 18)$ & $\$ 0,0001$ & $\bullet$ & $178(92 \%)$ & $1 \cdot 39(1.14-1.69)$ & 0.001 & 10r & $2.6(1.0$ to 4.2$)$ & 0.002 & F-1 \\
\hline & & & & & $\begin{array}{lllll} & 1 & 1 & 1 & \\
1 & 2 & 5 & 10 & 50\end{array}$ & & & & $\begin{array}{lll}1 & 1 & 1 \\
1 & 2 & 3\end{array}$ & & & ${ }_{10}^{10} 15$ \\
\hline & & & & & Hazard ratio & & & & Hazard ratic & & & Time (years) \\
\hline
\end{tabular}

FIGURE 6. Risk of respiratory and total mortality according to the type of obstructive lung disease (reproduced with permission from Lange P et al. $\left.{ }^{44}\right)$.

ACO: asthma-chronic obstructive pulmonary disease overlap; BMI: body-mass index; Cl: confidence interval; COPD: chronic obstructive pulmonary disease; $\mathrm{FEV}_{1}$ : forced expiratory volume in one second.

$\mathrm{ACO}$ with late-onset asthma and this group also had shortest life expectancy (Fig. 6). We concluded that the prognosis of individuals with ACO seems to be affected by the age of recognition of asthma, being worst in those with asthma onset after 40 years of age ${ }^{44}$.

\section{BIOMARKERS}

There is a need for biomarkers in COPD. Spirometry is required for diagnosis and contains information for categorisation and determining the prognosis; however, the heterogeneity of COPD makes $\mathrm{FEV}_{1}$ alone a poor disease characteristic $^{45}$. Markers of systemic inflammation were believed to be of value for predicting prognosis, disease progression and possibly other concomitant diseases. Fibrinogen was in the CCHS associated with level of $\mathrm{FEV}_{1}$ and risk of hospital admission as well as decline in $\mathrm{FEV}_{1}{ }^{46}$. Whereas the latter has not been confirmed in longitudinal studies of COPD patients ${ }^{40}$, fibrinogen is now accepted as a marker of increased risk of exacerbations ${ }^{47}$. C-reactive protein (CRP) is also associated with lung function and risk of admission $^{48}$ and more detailed analysis using the concept of Mendelian randomisation showed that it is not elevated CRP per se that carries the risk, but rather underlying factors affecting both CRP and risk $^{49}$. As it is unlikely that a single biomarker will ever fulfil all expectations in COPD, patterns of biomarkers have been examined. Using three levels of three easily accessible inflammatory biomarkers 
- white blood cell count, fibrinogen and CRP - we found a clear association between increased systemic inflammation and risk of a number of important comorbidities in $\mathrm{COPD}^{50}$. Using the same biomarkers, we also found that systemic inflammation was associated with exacerbations, even after adjusting for history of exacerbations ${ }^{51}$. However, as exacerbations are rare events on a population level, it was the negative predictive value rather than the positive predicted value that was of importance. That patterns of inflammation rather than single markers may be of predictive value in COPD was also to some extent seen in the Evaluation of COPD Longitudinally to Identify Predictive Surrogate End-points (ECLIPSE) study of patients with moderate-to-very-severe $\mathrm{COPD}^{52,53}$.

Blood eosinophils have attracted significant attention recently as it may be a theragnostic marker for ICS in COPD. This is difficult to evaluate in epidemiology. However, population studies can add to the general knowledge of this biomarker, and in Copenhagen, blood eosinophils were associated with an increased risk in both asthma ${ }^{54}$ and COPD $^{55}$; for the latter, absolute counts had better predictive value than relative eosinophil counts, with optimal prediction cut off at $340 \times 10^{9}$ cells/L. Recently, we have also shown that eosinophils are associated with an increased risk of pneumonia without any obvious interaction with treatment with ICS ${ }^{56}$.

\section{THE COPENHAGEN CITY LUNG STUDY}

As mentioned, treatment effects can be difficult to assess in observational studies as not least bias by indication can be difficult to adjust for. We assessed the effect of statins on risk of exacerbation and found a protective effect with statins reducing the risk of exacerbations by $33 \% 57$. This contrasts with the findings of the Simvastatin Therapy for Moderate and Severe COPD (STATCOPE) trial ${ }^{58}$ and subsequent analyses actually confirmed that the effect was only seen in those excluded from the randomised trial: i.e., those where statins may already be indicated for cardiovascular reasons.

It is, nevertheless, possible to do randomised controlled trials nested in a population study. The advantage is that this can often reduce the recruitment bias often seen in controlled trials ${ }^{59,60}$; the downside is that any marked intervention effect may affect subsequent observational follow-up findings. With the remarkable impact of ICS on course and prognosis in asthma and Dutch studies indicating an effect of systemic steroids on the prognosis of $\mathrm{COPD}^{61,62}$, the path was opened for long-term controlled trials of ICS in COPD with disease progression as the outcome. In parallel with the European Respiratory Society Study on Chronic Obstructive Pulmonary Disease (EUROSCOP) $)^{63}$ and the Inhaled Steroids in $\mathrm{Ob}$ structive Lung Disease in Europe (ISOLDE) trial $^{64}$, we chose to examine the effect of a relatively high dose of inhaled budesonide on $\mathrm{FEV}_{1}$ decline in subjects in the Copenhagen Heart Study with irreversible airflow limitation $^{65}$. This study was called the Copenhagen City Lung Study and investigated lung function decline during three years in 290 patients who were randomly assigned to budesonide, $800 \mu \mathrm{g}$ plus $400 \mu \mathrm{g}$ daily for six months followed by $400 \mu \mathrm{g}$ twice daily. The estimated rates of decline did not differ significantly 
(difference $3 \mathrm{ml} / \mathrm{yr}$ ). In this population with quite mild COPD, we observed 155 exacerbations in the budesonide group and 161 in the placebo group. Thus, the results of the Copenhagen City Lung Study added to the rather pessimistic view on ICS in mild COPD, possibly worth revisiting after recent trials and re-analyses ${ }^{66-68}$.

\section{COMMENT}

A longitudinal study is often known from its scientific outputs; however, the real work does not come from the analyses and manuscripts but from the daily running of the study and the goodwill of the participants and their willingness to invest time in the examinations. The CCHS benefitted from starting at a time when the willingness to participate was likely higher than today where attrition rates seem to be shrinking. Also, staff loyal to the study has ensured the continuity and stability and has helped overcome challenges over the years - but things like change of spirometer, changing register coding (changing of International Classification of Diseases [ICD] codes), and changing legislation have provided occasional headaches. In an ideal world not least a world with better research funding - more frequent examinations with more time for each participant would have been desirable, but all in all this study has served its purpose well.

Finally, we have had the luxury of only summarising the respiratory research in the CCHS. Many hundreds of papers in other areas have been published; searches on authors like Gorm Jensen, Peter Schnohr, Børge Nordestgaard, Eva Prescott and Merete Appleyard will provide a long list of publications, not least in the cardiovascular area.

\section{CONCLUSIONS}

The longitudinal nature, the considerable size and the possibility of linking study data with various Danish health registries have allowed the CCHS to publish more than 100 papers on different aspects of asthma and COPD during the last 30 years. In particular, the CCHS has contributed to a better understanding of factors affecting the development, the course of lung function and the prognosis of this disease.

\section{CONFLICTS OF INTEREST}

Dr. Lange reports personal fees from Chiesi Pharmaceuticals, personal fees from Boehringer-Ingelheim, personal fees from AstraZeneca, grants and personal fees from GSK, outside the submitted work; Dr. Vestbo reports personal fees from Chiesi Pharmaceuticals, personal fees from Boehringer-Ingelheim, personal fees from Novartis, personal fees from AstraZeneca, outside the submitted work.

\section{REFERENCES}

1. Fletcher CM, Peto R, Tinker CM, Speizer FE. The natural history of chronic bronchitis and emphysema. Oxford: Oxford University Press; 1976.

2. Fletcher C, Peto R. The natural history of chronic airflow obstruction. BMJ. 1977;1:1645-8.

3. Higgins MW, Keller JB. Seven measures of ventilatory lung function. Population values and a comparison of their ability to discriminate between persons with and without chronic respiratory symptoms and disease, Tecumseh, Michigan. Am Rev Respir Dis. 1973;108: 258-72.

4. Monto AS, Higgins MW, Ross HW. The Tecumseh study of respiratory illness. VIII. Acute infection in chronic respiratory disease and comparison groups. Am Rev Respir Dis. 1975;111:27-36.

5. Stone RW, Comstock GW, Tonascia JA, Chandra V. Predictive value of respiratory findings. Bull Eur Physiopathol Respir. 1978;14:189-96. 
6. Lebowitz MD, Burrows B. The relationship of acute respiratory illness history to the prevalence and incidence of obstructive lung disorders. Am J Epidemiol. 1977;105:544-54.

7. Dawber TR, Meadors GF, Moore FE, Jr.: Epidemiological approaches to heart disease: the Framingham Study. Am J Public Health 1951; 41:279-286

8. Appleyard M. The Copenhagen City Heart Study. Scand J Soc Med. 1989; Suppl. 41.

9. Kohansal R, Soriano JB, Agusti A. Investigating the natural history of lung function: Facts, pitfalls, and opportunities. Chest. 2009;135:1330-41.

10. Ashley F, Kannel WB Sorlie PD, Masson R. Pulmonary function: Relation to aging, cigarette habit, and mortality: The Framingham Study. Ann Intern Med. 1975;82:739-45.

11. Lange P, Groth S, Mortensen J, Appleyard M, Nyboe J, Jensen G, Schnohr $\mathrm{P}$. Decline of $\mathrm{FEV}_{1}$ related to the type of tobacco smoked and inhalation. Thorax. 1990;45:22-6.

12. Lange P, Groth S, Mortensen J, Appleyard M, Nyboe J, Jensen G, Schnohr P. Determinants of chronic mucus hypersecretion with special reference to the type of tobacco smoked. Int J Epidemiol. 1989;18:882-7.

13. Lange P, Groth S, Mortensen J, Appleyard M, Nyboe J, Jensen G, Schnohr $\mathrm{P}$. The effects of smoking and changes in smoking habits on decline of FEV $\mathrm{F}_{1}$. Eur Respir J. 1989;2:811-6.

14. Lange P, Groth S, Mortensen J, Appleyard M, Nyboe J, Jensen G, Schnohr P. Phlegm production in plain cigarette smokers who changed to filter cigarettes or quitted smoking. J Int Med. 1990.228:115-20.

15. Prescott E, Bjerg AM, Andersen PK, Lange P, Vestbo J. Gender differences in smoking effects on lung function and risk of hospitalisation from chronic obstructive lung disease. Eur Respir J. 1997;10:822-7.

16. Løkke A, Lange P, Scharling H, Fabricius P, Vestbo J. Developing CORD - a 25 years follow-up study of the general population. Thorax. 2006;61:935-9.

17. Lundbäck B, Lindberg A, Lindström $M$ et al. Not 15 but $50 \%$ of smokers develop COPD?--Report from the Obstructive Lung Disease in Northern Sweden Studies. Respir Med. 2003;97:115-22.

18. Calle EE, Thun MJ, Petrelli JM, Rodriguez C, Heath CW. Body-Mass Index and mortality in a prospective cohort of U.S. adults. N Engl J Med. 1999; 341:1097-1105.

19. Jee SH, Sull JW Park J, Lee S-Y Ohrr H Guallar E, Samet JM. Body-Mass Index and Mortality in Korean Men and Women. N Engl J Med 2006.355:779-87.

20. Landbo C, Prescott E, Lange P, Vestbo J, Almdal TP. Prognostic value of nutritional status in chronic obstructive pulmonary disease. Am J Respir Crit Care Med. 1999;160:1856-61.

21. Prescott E, Almdal T, Mikkelsen KL, Tofteng CL, Vestbo J, Lange P. Prognostic value of weight change in chronic obstructive pulmonary disease: Results from the Copenhagen City Heart Study. Eur Respir J. 2002;20: 539-44.

22. Prescott E, Lange P, Vestbo J and the Copenhagen City Heart Study Group. Socioeconomic status, lung function, and admission to hospital for COPD. Results from the Copenhagen City Heart Study. Eur Respir J. 1999;13: 1109-14.

23. Prescott E, Godtfredsen N, Vestbo J, Osler M. Social position and mortality from respiratory diseases in males and females. Eur Respir J. 2003;21:821-6.

24. Lange P, Marott JL, Vestbo J, Ingebrigtsen TS, Nordestgaard BG. Socioeconomic Status and Prognosis of COPD in Denmark. COPD. 2014;11:431-7.

25. Garcia-Aymerich J, Lange P, Benet M, Schnohr P, Anto JM, Regular physical activity reduces hospital admission and mortality in chronic obstructive pulmonary disease: a population-based cohort study. Thorax. 2006;61:772-8.

26. Garcia-Aymerich J, Lange P, Benet M, Schnohr P, Auto JM, Regular physical activity modifies smoking-related lung function decline and reduces risk of COPD. A Population based cohort study. Am J Respir Crit Care Med. 2007;175:458-63.

27. Vaes AW, Garcia-Aymerich J, Marott JL et al. Changes in physical activity and all-cause mortality in COPD. Eur Respir J. 2014;44:1199-209.

28. Ingebrigtsen TS, Marott JL, Vestbo J, Nordestgaard BG, Hallas J, Lange P. Gastro-esophageal reflux disease and exacerbations in chronic obstructive pulmonary disease. Respirology. 2015;20:101-7.
29. Peto R, Speizer FE, Cochrane AL et al. The relevance in adults of air-flow obstruction, but not of mucus hypersecretion, to mortality from chronic lung disease. Am Rev Respir Dis. 1983;128:491-500.

30. Lange P, Nyboe J, Appleyard M, Jensen G, Schnohr P. The relation of ventilatory impairment and of chronic mucus hypersecretion to mortality from obstructive lung disease and from all causes. Thorax. 1990;45:579-85.

31. Prescott E, Lange P, Vestbo J. Chronic mucus hypersecretion in COPD and death from pulmonary infection. Eur Respir J. 1995;8:1333-8.

32. Lange P, Vestbo J, Nyboe J. Risk factors for death and hospitalisation from pneumonia. A prospective study of a general population. Eur Respir J. 1995;8:1694-8.

33. Vestbo J, Prescott E, Lange P, and The Copenhagen City Heart Study Group. Association of chronic mucus hypersecretion with $\mathrm{FEV}_{1}$ decline and COPD morbidity. Am J Respir Crit Care Med. 1996;153:1530-5.

34. Pauwels R, Buist A, Calverley P, Jenkins C, Hurd S. Global strategy for the diagnosis, management, and prevention of chronic obstructive pulmonary disease. NHLBI/WHO global initiative for chronic obstructive lung disease (GOLD) workshop summary. Am J Respir Crit Care Med. 2001;163:1256-76.

35. Vestbo J, Lange P. Can GOLD Stage 0 provide information of prognostic value in chronic obstructive pulmonary disease? Am J Respir Crit Care Med. 2002;166:329-32.

36. Lange P, Parner J, Vestbo J, Jensen G, Schnohr P. A 15-yr follow-up of ventilatory function in adults with asthma. N Engl J Med. 1998;339:1194-1200.

37. Vestbo J, Hurd SS, Agusti AG, Jones PW et al. Global Strategy for the Diagnosis, Management and Prevention of Chronic Obstructive Pulmonary Disease, GOLD Executive Summary. Am J Respir Crit Care Med. 2013; 187:347-65.

38. Lange P, Marott JL, Vestbo J, Olsen KR, Ingebrigtsen TS, Dahl M, Nordestgaard BG. Prediction of the clinical course of chronic obstructive pulmonary disease, using the new GOLD classification: a study of the genera population. Am J Respir Crit Care Med. 2012;186:975-81.

39. Celli BR, Thomas NE, Anderson JA et al. Effect of pharmacotherapy on rate of decline of lung function in COPD: Results from the TORCH study. Am J Respir Crit Care Med. 2008;178:332-8

40. Vestbo J, Edwards LD, Scanlon PD et al. Change in forced expiratory volume in 1 second over time in COPD. N Engl J Med. 2011;365:1184-92.

41. Casanova C, de Torres JP, Aguirre-Jaíme A et al. The progression of chronic obstructive pulmonary disease is heterogeneous. The experience of the BODE cohort. Am J Respir Crit Care Med. 2011;184:1015-21.

42. Nishimura M, Makita $H$, Nagai $K$ et al. Annual change in pulmonary function and clinical phenotype in chronic obstructive pulmonary disease. Am J Respir Crit Care Med. 2012;185:44-52.

43. Lange P, Celli B, Agustí A et al. Lung-Function Trajectories Leading to Chronic Obstructive Pulmonary Disease. N Engl J Med. 2015;373:111-22.

44. Lange P, Çolak Y, Ingebrigtsen TS, Vestbo J, Marott JL. Long-term prognosis of asthma, chronic obstructive pulmonary disease, and asthma-chronic obstructive pulmonary disease overlap in the Copenhagen City Hear study: a prospective population-based analysis. Lancet Respir Med. 2016;4 454-62.

45. Agustí A, Calverley PMA, Celli B et al. Characterization of COPD heterogeneity in the ECLIPSE cohort. Respir Res. 2010;11:122.

46. Dahl M, Tybjærg-Hansen A, Vestbo J, Lange P, Nordestgaard BG. Elevated plasma fibrinogen associated with reduced pulmonary function and increased risk of Chronic Obstructive Pulmonary Disease. Am J Respir Crit Care Med. 2001;164:1008-11.

47. Mannino DM, Tal-Singer R, Lomas DA et al. Plasma Fibrinogen as a Biomarker for Mortality and Hospitalized Exacerbations in People with COPD. Chronic Obstr Pulm Dis. 2015;2:23-34.

48. Dahl M, Vestbo J, Lange P, Bojesen SE, Tybjærg-Hansen A, Nordestgaard BG. C-reactive protein as a predictor of prognosis in COPD. Am J Respir Crit Care Med. 2006:175:250-5

49. Dahl M, Zacho J, Vestbo J, Lange P, Nordestgaard BG. C-reactive protein and chronic obstructive pulmonary disease: A Mendelian randomisation approach. Thorax. 2011;66:197-204. 
50. Thomsen M, Dahl M, Lange P, Vestbo J, Nordestgaard BG. Inflammatory biomarkers and comorbidities in chronic obstructive pulmonary disease. Am J Respir Crit Care Med. 2012;186:982-8.

51. Thomsen M, Ingebrigtsen TS, Marott JL, Dahl M, Lange P, Vestbo J, Nordestgaard BG. Inflammatory biomarkers and exacerbations of chronic obstructive pulmonary disease. JAMA. 2013;309:2353-61.

52. Hurst JR, Vestbo J, Anzueto A et al. Susceptibility to Exacerbation in Chronic Obstructive Pulmonary Disease. N Engl J Med. 2010;363:1128-38.

53. Agusti A, Edwards LD, Rennard SI et al. Persistent systemic inflammation is associated with poor clinical outcomes in COPD: A novel phenotype. PLoS ONE. 2012;7:e37483.

54. Vedel-Krogh S, Nielsen SF, Lange P, Vestbo J, Nordestgaard BG. Association of Blood Eosinophil and Blood Neutrophil Counts with Asthma Exacerbations in the Copenhagen General Population Study. Clin Chem. 2017;63: 823-32.

55. Vedel-Krogh S, Nielsen SF, Lange P, Vestbo J, Nordestgaard BG. Blood Eosinophils and Exacerbations in COPD: the Copenhagen General Population Study. Am J Respir Crit Care Med. 2016;193:965-74.

56. Vedel-Krogh S, Nordestgaard BG, Lange P, Vestbo J, Nielsen SF. Blood eosinophil count and risk of pneumonia hospitalisations in individuals with COPD. Eur Respir J. 2018;51: pii: 1800120.

57. Ingebrigtsen TS, Marott JL, Nordestgaard BG, Lange P, Hallas J, Vestbo J. Statin use and exacerbations in individuals with chronic obstructive pulmonary disease. Thorax. 2015; 70: 33-40.

58. Criner GJ, Connett JE, Aaron SD, et al. Simvastatin for the prevention of exacerbations in moderate-to-severe COPD. N Engl J Med 2014; 370: 2201-10.

59. Herland K, Akselsen JP, Skjönsberg $\mathrm{OH}$, et al. How representative are clinical study patients with asthma or COPD for a larger "real life" population of patients with obstructive lung disease? Respir Med 2005; 99: 11-19.
60. Woodcock A, Boucot I, Leather DA, Crawford J, Collier S, Bakerly ND, Hilton E, Vestbo J. Effectiveness versus efficacy trials in COPD: how study design influences outcomes and applicability. Eur Respir J 2018; 51: 1701531; DOI: $10.1183 / 13993003.01531-2017$

61. Postma DS, Steenhuis EJ, van der Weele LT, Sluiter HJ. Severe chronic airflow obstruction: can corticosteroids slow down progression? Eur J Respir Dis 1985; 67: 56-64.

62. Postma DS, Peters I, Steenhuis EJ, Sluiter HJ. Moderately severe chronic airflow obstruction: can corticosteroids slow down progression? Eur Respir J 1988; 1: 22-26.

63. Pauwels RA, Löfdahl CG, Laitinen LA, Schouten JP, Postma DS, Pride NB, et al.; European Respiratory Society Study on Chronic Obstructive Pulmonary Disease. Long-term treatment with inhaled budesonide in persons with mild chronic obstructive pulmonary disease who continue smoking. N Engl J Med. 1999;340:1948-53.

64. Burge PS, Calverley PM, Jones PW, Spencer S, Anderson JA, Maslen TK Randomised, double blind, placebo controlled study of fluticasone propionate in patients with moderate to severe chronic obstructive pulmonary disease: the ISOLDE trial. BMJ. 2000;320:1297-1303.

65. Vestbo J, Sørensen T, Lange P, Brix A, Torre P, Viskum K. Long-term effect of inhaled budesonide in mild and moderate chronic obstructive pulmonary disease - a randomised, controlled trial. Lancet. 1999;353:1819-23.

66. Celli BR, Thomas NE, Anderson JAet al. Effect of pharmacotherapy on rate of decline of lung function in COPD: Results from the TORCH study. Am J Respir Crit Care Med. 2008;178:332-8.

67. Vestbo J, Anderson JA, Brook RDet al. Fluticasone furoate and vilanterol and survival in chronic obstructive pulmonary disease with heightened cardiovascular risk (SUMMIT): a double-blind randomised controlled trial. Lancet. 2016;387:1817-26.

68. Barnes NC, Sharma R, Lettis S, Calverley PM. Blood eosinophils as a marker of response to inhaled corticosteroids in COPD. Eur Respir J. 2016;47:1374-82. 